\title{
DOS PARANGOLÉS À ERA DIGITAL: O LEITOR NAS ARTES INTERATIVAS
}

\section{FROM PARANGOLÉS TO DIGITAL AGE: THE READER IN INTERACTIVE ARTS}

\begin{abstract}
José Tonezzi ${ }^{1}$
Aluizio Guimarães ${ }^{2}$

Resumo: A partir das características da arte interativa, a reflexão pondera sobre esta manifestação em tempos de relações multimidiáticas, em que equipamentos e programas digitais se impõem na relação humana com o mundo. A partir disto, tratamos de uma possível interação entre a obra de arte digital e o espectador que, na condição de leitor interator, pode também atuar no processo de criação e interferir no resultado da obra. Visando contribuir com os estudos da leitura contemporânea, estipula-se aqui um conjunto de questionamentos sobre a manifestação artística de um futuro breve.
\end{abstract}

Palavras chave: Interator; artes interativas; arte e mídia.

Abstract: From the characteristics of interactive art, the reflection ponders about this manifestation in times of multimedia relations, in which digital equipment and programs impose themselves on the human relationship with the world. From this, we deal with a possible interaction between the digital artwork and the spectator who, as an interacting reader, can also act in the creation process and interfere in the result of the work. In order to contribute to the studies of contemporary reading, a set of questions is stipulated here about the artistic manifestation of a near future.

Keywords: Interactor; interactive arts; art and media.

Uma produção artística que estimule a participação do observador em sua composição traz em si o caráter de obra de arte interativa. É o caso em que o fator maior incide na relação entre o apreciador e a obra observada. No decorrer do século XX é quando se nota a prática de efetiva interatividade, sendo um bom exemplo a chamada arte cinética, em que obras diversas pedem a intervenção física do observador. Ou seja, trata-se de levar o apreciador a uma função ativa na concepção de uma obra de arte que, sem a intervenção dele, não se dá.

Esta prática se intensificou, chegando a alterar um costume já tradicional em espaços de exposição e apresentações artísticas. Contrapondo-se ao aviso É proibido tocar na obra, exibido em tabuletas de galerias de arte, houve o convite ao observador para relacionar-se com o que se apresentava. Hoje, a fim de que a obra aconteça, em determinadas espaços é sugerido o uso de mídias de comunicação digital. Mais do que um produto acabado, é possível que a obra ganhe caráter de evento, aproximando-se do que Umberto Eco (2001) chama obra aberta. Neste âmbito, trabalhos de Hélio Oiticica (1937-1980) e Lygia Clark (1920-1988) mostram-se como boas referências.

No amplo leque das manifestações artísticas das últimas décadas, o advento das artes eletrônicas e de implementos computacionais abrem a possibilidade de que o observador/espectador ganhe novas condições de leitura e interatividade. Além de intervir e/ou inserir-se fisicamente na obra, como acontece em diversas manifestações artísticas, nota-se que

\footnotetext{
${ }^{1}$ Universidade Federal da Paraíba.

${ }^{2}$ Universidade Federal de Campinas Grande.
} 
novas formas de interação com ela se abrem com o uso de programas que permitem a imersão no terreno da chamada realidade mista, soma da realidade física com a realidade virtual. Então o observador da obra será levado à hipersuperfície, conforme observa Gabriella Giannachi:

A hipersuperfície é onde o real e o virtual se encontram. É materialidade e textualidade, real e representação. É também o lugar da performance virtual. Através da hipersuperfície, o espectador pode entrar na obra de arte, fazer parte dela e também interagir com ela. Porque a hipersuperfície é um espaço liminar, o espectador pode dobrar sua presença e estar simultaneamente no ambiente real e no virtual. ${ }^{3}$ (GIANNACHI, 2004, p. 95)

Assim, a tela de equipamentos digitais poderá se configurar como portal de acesso a um território de criação. Um lugar em que o sujeito - denominado interator -, além de visualizar o processo de criação de uma obra, poderá interferir e se relacionar com ela, que permanecerá disponível para um constante processo de composição, aberta e possivelmente nunca finalizada.

Nesses tempos, em que um sem número pessoas tem parte da vida e das relações socias na hipersuperfície, variadas questões se colocam: o que lê um leitor interator? Onde - ou de onde - ele pode ele fazer a sua leitura? Como compor uma escrita reticente, que convide o leitor a alterar o seu desenvolvimento e consequentes resultados? Quem - e por quê - escreve para este novo tipo de leitor e possível coautor?

\section{Ler de tudo}

Dentre muitos conceitos, pode-se entender a escrita como uma expressão sígnica, um possível agrupamento de códigos que dão a entender um pensamento, uma mensagem ou a descrição de algum acontecimento. Tratamos aqui de fenômenos de leitura e escrita que emergem do universo das artes, sendo importante observar que compreendemos cada obra como um texto a ser lido, conforme expõe Claus Clüver:

Quero aqui apenas indicar que, sobretudo entre semioticistas, uma obra de arte é entendida como uma estrutura sígnica - geralmente complexa -, o que faz com que tais objetos sejam denominados "textos", independente do sistema sígnico a que pertençam. Portanto, um balé, um soneto, um desenho, uma sonata, um filme e uma catedral, todos figuram como "textos" que se "leem"; o mesmo se pode dizer de selos postais, uma procissão litúrgica e uma propaganda na televisão. (CLÜVER, 2006, p. 19)

\section{E como conceitua Umberto Eco:}

Obra aberta como proposta de um "campo" de possibilidades interpretativas, como configuração de estímulos dotados de uma substancial indeterminação, de maneira a induzir o fruidor a uma série de "leituras" sempre variáveis; estrutura, enfim, como "constelação" de elementos que se prestam a diversas relações recíprocas. (ECO, 2001, p. 150)

\footnotetext{
3 The hypersurface is where the real and the virtual meet each other. It is materiality and textuality, real and representation. It is also the site of virtual performance. Through the hypersurface, the viewer can enter the work of art, be part of it, as well as interact with it. Because the hypersurface is a liminal space, the viewer can double their presence and be in both the real and the virtual environment simultaneously. (Tradução livre conf. GIANNACHI, 2004, p. 95).
} 
Ou ainda como pondera Augusto Boal (2009): "A arte pensa o sentimento e sente o pensamento. Procura conhecer a palavra como objeto sensível, transformando palavras em poesia, pois a poesia está na sintaxe e não no léxico, como a música está na sequência de notas musicais e não em cada uma." (p. 93).

O fato é que, mesmo antes da fala, diante da necessidade de expressar-se, o ser humano se valia de arranjos para constituição de sinais materiais. Ao que parece, a relação humana com o mundo sempre se deu através da percepção de sinais naturais ou da composição deles para a comunicação. Sendo a escrita um conjunto de códigos, a leitura se impõe como ato de decodificação. Assim, o leitor detém sobretudo a função de decodificador, que se vê hoje em constante relação com signos múltiplos e dinâmicos, de natureza diversa. O surgimento dos meios de comunicação de massa e a posterior convergência das mídias - fala e escrita com transmissão e recepção de sons e imagens através de um mesmo equipamento - impuseram a necessidade de um agente que fosse além da decodificação, atuando também na operação de equipamentos e sistemas complexos, externos a ele.

A popularização do acesso às mídias digitais decorreu no que Vilém Flusser (2017) denomina mundo codificado, chegando mesmo a propor uma filosofia do design. Neste mundo é comum que um texto a ser lido se dê por meios diferentes e simultâneos, envolvendo variados programas e aplicativos que se valem de linguagens diversas, numa relação e jogo contínuo com o tempo, com o corpo e com o espaço, agora redimensionados. Trata-se de uma escrita híbrida, resultante de variadas estratégias que para a leitura requerem componentes sensoriais, levando o leitor ao desenvolvimento de condições outras a fim de cumprir com a leitura de códigos simultâneos, de variados perfis.

Conforme Clüver (2006), no âmbito das artes contemporâneas, o uso de mídias permite classificar a criação como sendo multimídia, mixmídia ou ambas. Um texto multimídia compõe-se de códigos de linguagens múltiplas, diferentes mas coerentes, coerentes mas separáveis. Já um texto mixmídia contém códigos complexos em mídias diferentes que não alcançariam coerência ou autossuficiência fora daquele contexto. Diante disto, pode-se vislumbrar outras características que, por vezes, nascem dos elementos expostos: imersão e interatividade.

\section{Obras imersivas e interativas}

Quando ao leitor é dada a possibilidade de interagir, há uma mudança na percepção da obra, uma vez que o olhar deixa de ser o único canal para tanto. Há uma relação a partir de ações interacionais, constituindo um fluxo de informações em duplo sentido, conforme Figura 1c.

Uma obra que faz uso da imersão torna possível adentrar nela, alterando o vetor que direciona o olhar daquele que a percebe, pois a leitura se dá no que seria o interior da obra, permitindo ao leitor imerso uma percepção em múltiplos sentidos, o que se constata na Figura 1a.

Enfim, ainda temos a condição daquele que está imerso em uma obra interativa, numa relação em que os vetores de leitura e relação são resultantes da fusão dos dois exemplos citados anteriormente. Além de estar imerso, o leitor também passa a interagir com a obra (Figura 1b). 
a)

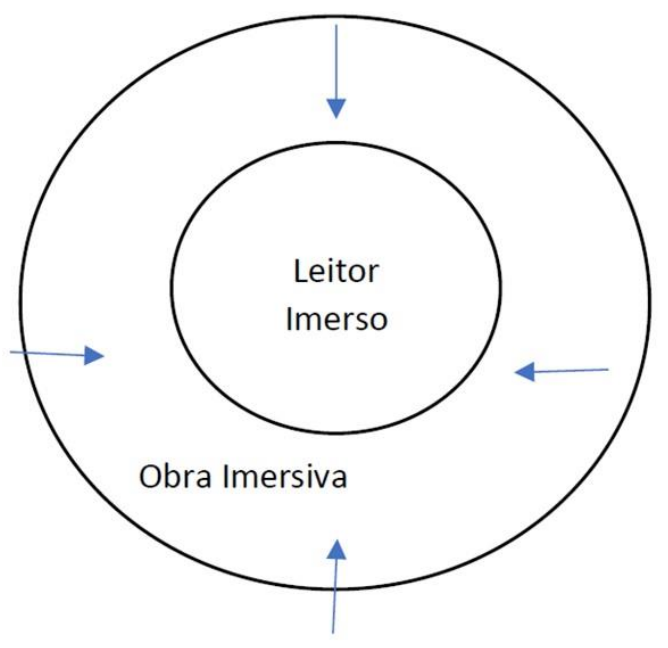

b)

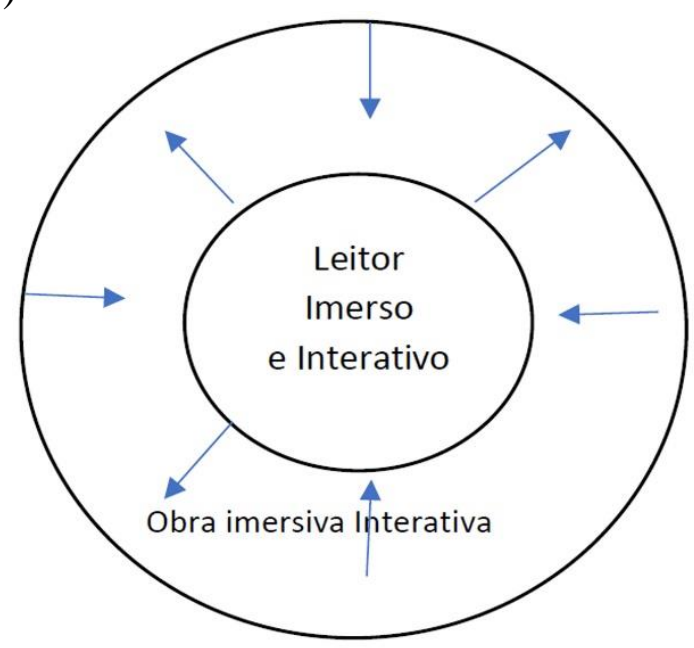

c)

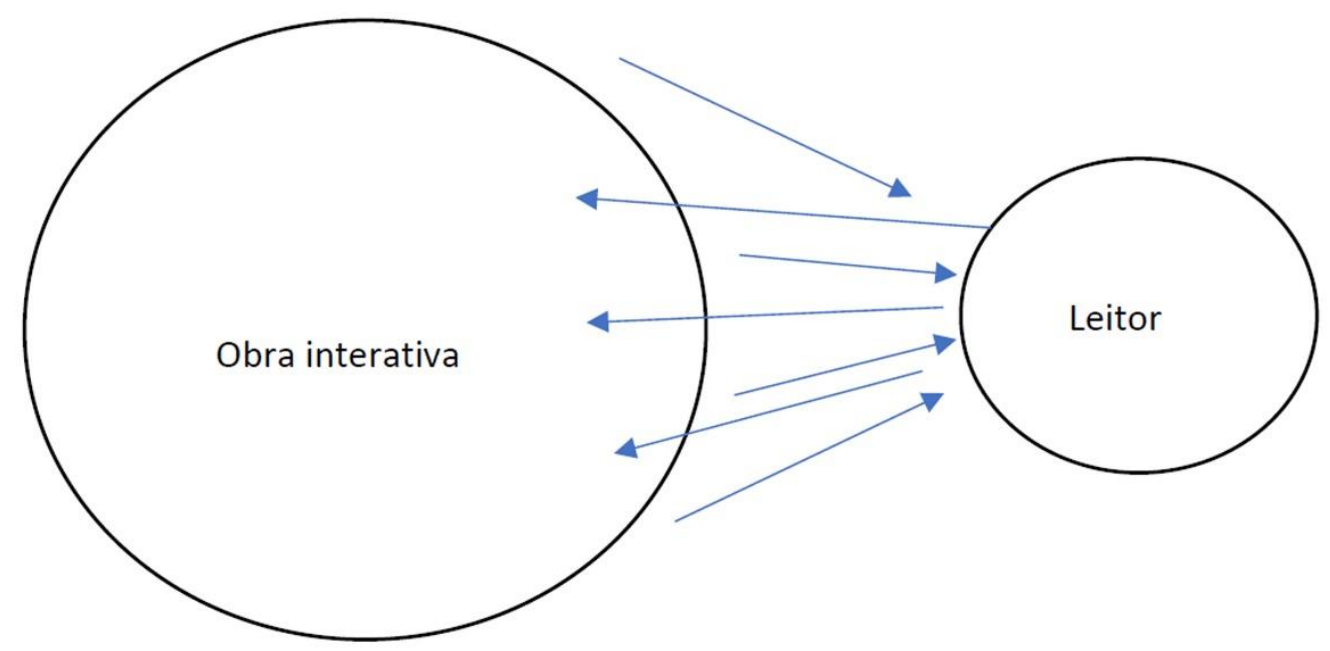

Figura 1 - Relação leitor e obra imersiva (a), leitor imerso em obra interativa (b) e leitura interativa. Fonte: os autores.

Vale aqui uma referência aos Parangolés, de Hélio Oiticica, que os tinha como obra "antiarte por excelência". Em princípio bastante vinculada ao ato de dançar, tida como abrigo, "penetrável" ou "obra-ambiente", de acordo com palavras do artista ${ }^{4}$, a obra se mostrava como um traje, algo a ser usado, um convite para que se a experimentasse, ganhando sentido apenas quando o observador, além da visão, ativasse em si outros sentidos de percepção. Uma obra vestível, como foi o caso de uma capa que continha fotos e textos, configurando-se como obraação multissensorial, que estreitava a relação com o apreciador.

Ao estimular uma leitura multissensorial, Oiticica buscava romper com a passividade do espectador, convidando-o a participar da atividade criadora. Portanto, os Parangolés eram também portais para universos subjetivos e interativos, em que o "eu" daquele que se relaciona com a obra e fundamentalmente a própria obra se tornassem ímpares no momento em que se dava aquele encontro. Assim, imersão e interatividade mostravam-se como matéria prima para este artista brasileiro da década de 1960. Como ilustrado na Figura 1c, Oiticica buscava alçar como protagonista não a obra acabada, em si, mas a relação material possível entre um abrigo e aquele que, estando imerso nele, pudesse com ele interagir. Ou, nas palavras do próprio artista,

\footnotetext{
${ }^{4}$ Disponível em: <https://www.correioims.com.br/carta/os-parangoles-de-helio-oiticica/>. Acesso em: 20/10/2019.
} 
“procurar um modo de dar ao indivíduo a possibilidade de 'experimentar', de deixar de ser espectador para ser participador."

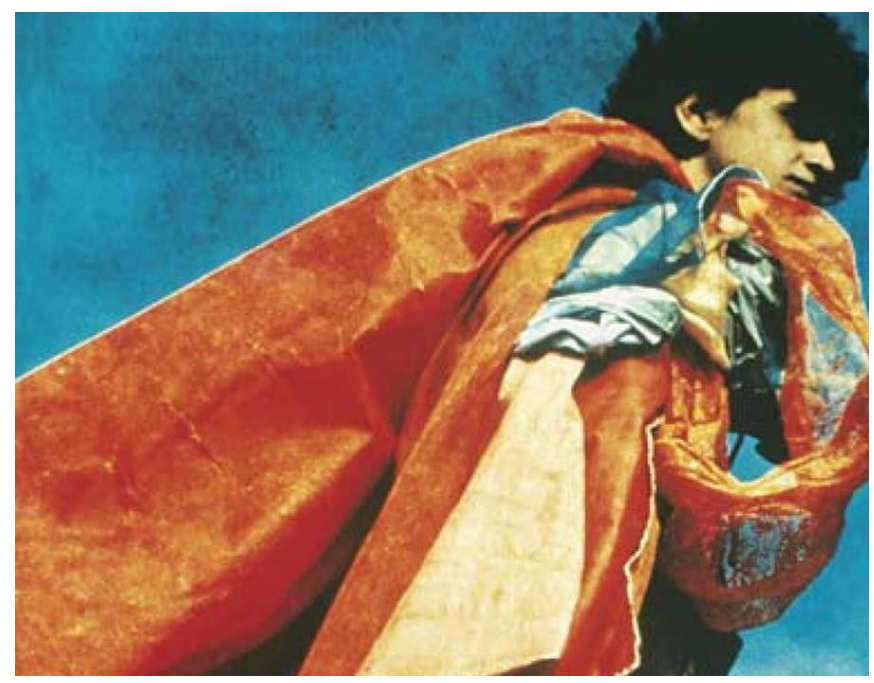

Figura 2 - Caetano Veloso trajando um Parangolé. ${ }^{6}$

Partindo do termo "obra-ambiente", conforme dizia Oiticica a respeito dos Parangolés, trataremos agora da criação em outro ambiente de leitura, no qual a obra também proporciona e requer imersão e interatividade. Trata-se do ambiente digital, em que a imersão se traduz como possível transposição e deslocamento do corpo e da presença, tornando possível que a leitura se dê em consonância com o ato de escrita, ou seja, com a composição e criação de conteúdo. As condições dadas para isto, entretanto, se efetiva no que Murray (1998) denomina ilusão de liberdade, em que o usuário age a partir de dados previamente combinados e com resultados pré-determinados. Ainda que com acontecimentos previamente estipulados, esta interação traz a sensação de autonomia plena na escolha e decisão para o destino do jogo.

Game e arte, termos cuja relação no mundo digital em princípio trouxe problemas, uma vez que intrinsecamente parecem nada ter em comum. Nas artes digitais, entretanto, é comum que artistas integrem jogos (games) e estruturas lúdicas em suas obras:

Desde o seu surgimento, os jogos têm permitido explorar grande parte dos paradigmas hoje presentes na arte interativa: navegação, simulação, hipertexto ou narrativa hipermídia, criação em universo 3D e ambientes multiusuários. Os jogos se dividem em vários gêneros: jogos de estratégia, jogos de tiro, jogos de ação, jogos em que o usuário vive um deus todo poderoso ("god games"). $^{7}$ (PAUL, 2008, p. 195-196)

Como num Parangolé, uma obra digital imersiva e interativa tem o leitor interator como parte dela. Ela está nele e ele está com ela, podendo interferir diretamente nos acontecimentos,

\footnotetext{
5 Retirado do texto "Parangolé: anti-obra de Hélio Oiticica" de Jardel Dias Cavalcanti. Disponível em: $\langle$ https://www.digestivocultural.com/colunistas/coluna.asp?codigo=856\&titulo=Parangole:_anti-obra_de_Helio_Oiticica> Acesso em: 15 de outubro de 2019.

${ }^{6}$ Disponível em: <https://arteref.com/gente-de-arte/o-que-foram-os-parangoles/>. Acesso em 20/10/2019.

${ }^{7}$ Dès leur apparition, em effet, les jeux ont permi d'explorer la plupart des paradigmes aujourd'hui présents dans l'art interactife: la navigation, la simulation, le récit hypertextuel ou hypermédia, la création d'univers 3D et les environements multi-utilisateurs. Les jeux se répartissent en plusieurs genres: jeux de stratégie, jeux de tir, jeux d'action, jeux où l'utilisateur incarne un dieu tout puissent ('god games'). (Tradução livre conf. PAUL, 2008, p. 195-196).
} 
que também interferem no seu comportamento e desejos de ação. Isto requer, por vezes, uma estratégia que favoreça a condição efetiva de interação e escrita conjunta, que envolva o sistema sensorial humano. Com isto, a leitura poderá envolver mídias visuais e sonoras, além de olfativas, gustativas e do tato, a depender do grau da imersão possibilitada pelos softwares e hardwares que forem utilizado. Com isto, o leitor não apenas estará imerso, mas literalmente exposto no espaço onde se dá a sua relação com a escrita. Trata-se aqui da composição de uma obra em que a Inteligência Artificial (IA) é de suma importância, pois que pode estimular e reger ações, reações e comportamentos, traduzidos em forma de algoritmos.

Problematizar a função daquele que, para ler uma escrita artística, nela precisa estar digitalmente inserido, para interagir e consequentemente intervir. Trata-se de uma discussão atual, referente a um leitor que, através de equipamento multimídia, opera na intersemiótico e na artemídia. Com isto, ele se torna parte de uma obra que se dá a partir de seus atos e escolhas.

\section{O leitor produtilizador}

Em mídias digitais, o uso de um programa puramente imersivo dá a ler um espaço diferenciado, de caráter virtual, como é possível, por exemplo, no programa Google Earth, lançado em 2001 e hoje bastante aprimorado. Já uma escrita imersiva interativa, além da presença nesse novo locus de ação, demanda a suspensão da passividade por parte do leitor, aproximando-o daquilo que Rancière (2010) chama espectador emancipado: "É preciso um teatro sem espectadores, no que quem assiste aprenda, em vez de ser seduzido por imagens, no qual quem assiste se torne participante ativo, em vez de ser um voyeur passivo.” (p. 10).

Num jogo previamente elaborado e levado a efeito no ato da interação, uma escrita interativa permite ao leitor jogar com ela, tendo a chance de alternar a sua forma de jogar e, a depender de sua atuação, transformar também a própria escrita em dimensões diversas. Em termos digitais, numa condição de uso de maiores opções e recursos, o leitor interator será chamado também produtilizador, uma vez que neste âmbito haverá, entre ele e a obra, o atributo da Inteligência Artificial, necessária para se ler, compor e alterar suas atitudes ou outros aspectos propostos como importantes pelo criador do programa gerador (obra base), assim como para o seu reprocessamento contínuo. O leitor produtilizador é o próprio interator em estágio de pós-interação direta com a obra, numa relação mediada pela Inteligência Artificial.

O uso da Inteligência Artificial na criação de obras artísticas interativas empresta os propósitos que levam à concepção de jogo de entretenimento, valendo-se dos interesses acadêmicos em detectar a operação do sistema e o seu desenvolvimento para chegar a tais resultados. Isto fortalece o diálogo entre arte e academia, justificando a presença de artistas nesse meio, assim como a de cientistas que operam na criação artística.

Sendo alguém que lê, podendo apagar o que está escrito e depois reescrever, num ato de criação simbiótica, o leitor produtilizador mostra-se como importante elemento para que uma obra de arte digital interativa possa existir. É possível dizer que, na composição de uma obra, ele chega a ser um potencial co-autor. Ele se alia ao criador da obra base, um artista que constrói a teia e disponibiliza um conjunto de possibilidades na escrita, onde as interferências do leitor serão ressignificadas e transformadas em algoritmos, incorrendo em composições que retornam para o leitor.

Como compor uma escrita que ofereça ao leitor a possibilidade de modificá-la? Até onde esta obra pertence a um artista específico? Qual o caráter de uma obra que pode valer-se de questões pessoais - portanto, da privacidade - do seu leitor? Até onde há uma condição ética nesta relação entre o propositor da obra base e o leitor? 
São muitas as questões que se levantam a partir do pensamento a respeito de uma obra de arte que se constitua num tempo em que a leitura do mundo se faz, cada vez mais, pela relação mediada em termos sociais e com a própria vida.

\section{Referências}

ASCOTT, Roy. Telematic Embrace. Edição: Edward A. Shanken. Los Angeles: University of California, 2003.

BERTHOLD, Margot. História Mundial do Teatro. São Paulo: Perspectiva, 2000.

BOAL, Augusto. A Estética do Oprimido. Rio de Janeiro: Garamond, 2009.

CLÜVER, Claus. Inter textus / Inter artes / Inter media. Aletria Revista de Estudos de Literatura, julho de 2006.

ECO, Umberto. Obra Aberta. São Paulo: Perspectiva, 2001.

FLUSSER, Vilém. $O$ mundo codificado: por uma filosofia do design e da comunicação. São Paulo: Ubu Editora, 2017.

GIANNACHI, Gabriella. Virtual Theatres. London: Routledge, 2004.

MURRAY, Janet. Hamlet on the Holodeck: the future of narrative in cyberspace. Cambridge: MIT Press, 1998.

PAUL, Christiane. L'art numérique. Paris: Thames \& Hudson, 2008.

RANCIÈRE, Jacques. O espectador emancipado. Lisboa: Orfeu Negro, 2010.

SANTAELLA, Lucia. Navegar no ciberespaço: o perfil do leitor imersivo. São Paulo: Paullus, 2004.

\section{Sobre os autores}

José Tonezzi é doutor em Artes Cênicas pela Universidade Federal do Estado do Rio de Janeiro (UNIRIO), com graduação em Artes Cênicas, mestrado em Psicologia da Educação e pósdoutorado pela Universidade Estadual de Campinas, com estudos na Université Paris 3 Sorbone Nouvelle, na França.

E-mail: tonezzi@hotmail.com.

Aluizio Guimarães é diretor teatral e dramaturgo, graduado em Comunicação Social pela Universidade Estadual da Paraíba (UEPB), Mestre em Computação, Comunicação e Artes e membro do Grupo de Pesquisa Teatro: Tradição e Contemporaneidade da Universidade Federal da Paraíba (UFPB). É Produtor Cultural da Universidade Federal de Campina Grande (UFCG) e membro do Conselho Estadual de Cultura da Paraíba.

E-mail: aluizioguimaraes2@gmail.com. 